\title{
HOMELESSNESS DURING THE COVID-19 PANDEMIC. STRATEGIES AND ACTION PLANS OF THE BERLIN SENATE
}

\author{
Sebastian Meier \\ Humboldt-Universität zu Berlin \\ Stargarder Straße 16, 10437, Berlin: Germany \\ meierseb@mail.de
}

\begin{abstract}
One of the social groups particularly hard hit by the COVID-19 pandemic is people experiencing homelessness, as they are especially vulnerable to infection with the severe acute respiratory syndrome coronavirus 2 (SARS-CoV-2). Still, the pandemic also drastically affected their livelihoods, as parts of municipal emergency assistance services have broken away. This article aims to highlight emergency responses of the Berlin Senate to people experiencing homelessness regarding COVID-19. The Senate is responding to the issue, among other things, by expanding and refiguring the existing contingent of shelters run by municipal emergency assistance services, preventing transmission of COVID-19 and treating those infected, and establishing mechanisms of tenant protection. The paper discusses to what extent Senate measures and interventions at the onset of the pandemic can address the emergent need for homeless assistance services in Berlin.
\end{abstract}

Keywords: Berlin Senate, COVID-19, critical urban geography, homelessness, housing, inequality, public health, social epidemiology.

\section{Introduction}

The risks of SARS-CoV-2 infection and the course of the COVID-19 disease and prevention measures are extremely unequally stratified among socioeconomic groups (Coughlin, Sandel \& Stewart, 2020; Baral et al., 2021). Thus, precisely the most vulnerable social groups were hit particularly hard by the COVID-19 pandemic. Existing disparities between social groups have been further exacerbated by the pandemic or have more severe consequences, e. g., risk of infection, mortality (Coughlin et al., 2020), access to medical services (Ray, 2020, April 9), or the financial burden (Harvey, 2020, March 20).

Socioeconomic factors highly influence prevalence and resilience. Hence, the issues above are much more dramatic for people experiencing homelessness or even sleeping rough.

In Germany, approximately 678,000 people were without housing during 2018 . The total number of homeless people for that year, excluding refugees recognized as homeless, was approx. 237,000 . Social agencies estimate the number of homeless recognized refugees at around 441,000 people. The number of people experiencing homelessness increased significantly compared to previous years (BAG W, 2019, November 11). In Berlin, a citywide census counted 1,972 people 
sleeping rough. However, professional associations assume that the number of unreported cases is much higher. Accordingly, estimates assume up to 10,000 people (Mieder, 2020, March 4).

For the duration of the COVID-19 pandemic, the Berlin Senate, in cooperation with social agencies, has taken measures to protect people experiencing homelessness and sleeping rough. Throughout the pandemic, a set of actions that differs from previous municipal assistance in scope and consistency has been put in place and requires closer examination. This article examines the need for action on homelessness assistance concerning the COVID-19 pandemic and scrutinizes the emergency responses of the Senate. Therefore, the question is what explicit actions and strategies the Berlin Senate undertake to protect people experiencing homelessness. To what extent can Senate measures and interventions at the onset of the pandemic address the emergent need for homeless assistance services in Berlin?

The first part of the contribution entails a review of existing literature on impacts to homelessness regarding COVID-19 and emergency responses in an international context. Subsequently, the author outlines problem-specific phenomena such as hidden homelessness and intersectionality. In a second section, the paper focuses on the study area of Berlin. It presents the municipal emergency assistance services, followed by a description of the main actors and their interdependencies with the Senate. Later sections deal with the research design and its limitations. Finally, the overall results are presented, discussed, and concluded.

\section{Literature background}

\section{Impact of COVID-19 on people experiencing homelessness}

People experiencing homelessness are more vulnerable to infection, its consequences, and societal changes. Thus, direct and indirect impacts caused by the COVID-19 pandemic are existential for this group in several ways. People experiencing homelessness are highly exposed, as their living situation hardly allows for a voluntary restriction of contact (Haesbaert, 2020). 'In the daily reality of those who experience homelessness, public health recommendations to physically distance, practice hand hygiene, wear masks, and get tested are not able to be met' (Baral et al., 2021, p. 929). The same is true, particularly for specific living conditions that can cause a rapid transmission of SARS-CoV-2 infection. According to Redditt, Wright, Rashid, Male and Bogoch, 'Homeless shelters (...) are densely populated environments, posing difficulties for physical distancing and intensifying risks for infectious disease outbreaks' (2020, p. E819). Numerous shelters had to reduce or completely cancel quotas due to applicable distance and hygiene protocols (SenIAS, 2020b, October 1). Even personal contact between aid workers and people experiencing homelessness was hardly possible (Rollmann, 2020).

Homeless people are also particularly vulnerable to SARS-CoV-2 infection because compared to other social groups they suffer significantly more frequently from pre-existing conditions and multiple illnesses (BAG W, 2020, November 6).

In principle, the health situation of people experiencing homelessness is already highly critical even without COVID-19, e.g. regarding the insufficiency of medical care and medical examinations, lack of hygiene, and malnutrition (Franke, 2015). In addition, homeless people are permanently exposed to weather conditions, with extreme temperatures and precipitation posing a particularly severe threat (Franke, 2015). Moreover, life on the street can be considered a trigger of mental and physical illnesses. 
Another critical point is that the pandemic has almost completely deprived homeless people of their livelihoods (Paula et al., 2020). Whereas homeless people could generate some income either by begging for small amounts of money or donations, this option is dramatically limited by the pandemic-induced restrictions, e.g., lower volumes of people in public spaces due to home office obligations. The possibility of generating income by collecting and returning deposit bottles has also become almost non-existent, as consumption in public spaces has declined sharply.

\section{Emergency responses to homelessness regarding COVID-19}

Scattered around the globe are examples of innovative and unprecedented actions to house and care for people experiencing homelessness during the COVID-19 pandemic. These include several approaches to provide housing.

In the United States, housing for homeless people took place in makeshift shelters in parking lots, mobile homes, trailers, and other facilities (Benavides \& Nukpezah, 2020). While some U.S. cities were renting empty hotels and motel rooms for homeless people (Perri, Dosani \& Hwang, 2020), other communities turned convention centers, gyms, and libraries into temporary shelters (Perri et al., 2020). For isolation or quarantine, several authorities in the U.S. have secured hotels to house people experiencing homelessness temporarily (Fuchs et al., 2021). Likewise, in Canada, isolation units and shelters were set up from hotels or community centers (Baral et al., 2021).

In England, the Ministry of Housing, Communities, and Local Government instructed all local authorities to move everyone sleeping rough and in communal shelters to a safe place. 'Nearly 15,000 people who were sleeping rough or at risk of doing so have subsequently been assisted into self-contained emergency accommodation in commercial hotels, B\&Bs, and hostels, and estimates that over $90 \%$ of rough sleepers known to councils at the beginning of the crisis have been offered accommodation' (Fitzpatrick, Watts \& Sims, 2020, p. 2). According to authorities, this campaign affected $90 \%$ of people sleeping rough ( Fitzpatrick et al., 2020).

South Africa tried to prevent SARS-CoV-2 transmission between people experiencing homelessness by a different spatial tactic. People experiencing homelessness were moved to stadia in the first place and later to parks (Oladimeji, Atiba, Mbokazi \& Hyera, 2020).

In Australia, four state governments provided mass emergency shelters for 40,000 rough sleepers and people experiencing homelessness (Pawson et al., 2021). A small number of those affected were able to be integrated into permanent housing.

In other countries, e. g. Brazil, the situation was highly problematic, not least because of the government. Help here came to a significant extent from non-governmental organizations and civil society (Nunes, Rodriguez \& Cinacchi, 2021). However, many governmental and non-governmental initiatives in India provided shelter and food for people experiencing homelessness. Nevertheless, governmental, community, and NGO levels need a coordinated effort (Banerjee \& Bhattacharya, 2021).

Apart from these numerous examples of temporary accommodation, there have been various approaches to prevent the loss of housing. The COVID-19 induced loss of jobs or short-time working and income losses are an essential threat for entire population groups and may cause the loss of housing. Australian authorities implemented rent and eviction moratoria and temporary income support (Pawson et al., 2021). Nonetheless, while at least a quarter of all private renters suffered income loss during the pandemic, only a small minority received a rent adjustment from their landlord (Pawson et al., 2021).

Another issue is the regular supply of people experiencing homelessness with food. This too has become much more problematic in the context of COVID-19. While some U.S. cities provided 
bag lunches and meals ready to eat, others deployed so-called Meal Hubs (Benavides \& Nukpezah, 2020). Nunes et al. (2021) stress the importance of civil society support and NGOs feeding people experiencing homelessness.

Some other crucial emergency responses were occurring strategies regarding preventive care and treatment in the context of COVID-19. In some parts of the U.S., handwashing stations and portable toilets were set up at known encampments (Benavides \& Nukpezah, 2020). The Canadian Network for the Health and Housing of the Homeless ( $\mathrm{CNH} 3$ ) stated six main tasks in response to this pandemic. These are 'enhanced screening methods, sentinel surveillance, coordination of health and shelter systems, COVID-19 risk stratification, isolation shelters for persons under investigation and cohorting SARS-CoV-2-positive cases for community-based shelter care' (Perri et al., 2020, p. E717).

Several studies have highlighted a higher need for emotional support among individuals experiencing homelessness during the pandemic (Banerjee \& Bhattacharya, 2021; Nunes et al., 2021). The sudden closing of social and public facilities, and the severance of social relationships, can harm the mental health of individuals experiencing homelessness (Perri et al., 2020). For this reason, for instance 'San Antonio connected a Hotline to help individuals reach social services as well as redeployed staff to interact with the homeless' (Benavides \& Nukpezah, 2020, p. 653f).

One emergency response countries worldwide have taken to contain the spread of COVID-19 has been to close country borders or impose entry restrictions. This shift has had significant consequences for migrants and refugees (Kluge, Jakab, Bartovic, d'Anna \& Severoni, 2020; WHO, 2020).

The examples show that the political responses to the pandemic and the epidemiological measures impose more significant restrictions on everyday life for certain social groups than for others. This issue will be discussed in more detail in the following chapter.

\section{Hidden homelessness and intersectionality}

The term hidden homelessness refers to people experiencing homelessness who live hidden or try to disguise the fact of homelessness and therefore do not appear in official statistics (OECD, 2021, May 27). The reason is that homeless people are victims of stigma, discrimination, and exclusion (Annen, 2020). According to Kauppert, 'the conceptualization of the group designation the homeless is subject to processes of simplification and generalization which affected persons themselves have little control over and which can serve as the basis for discriminatory behavior against the group' (2018, p. 25; translated by the author). The OECD states that '( $h$ )idden homelessness tends to be more prevalent among women, youth, LGTBI, victims of domestic abuse, asylum seekers, or people living in rural areas and smaller communities' (2021, May 27, p. 10).

Coughlin et al. (2020, p. 8) found for the U.S. that '(a)mong families experiencing homelessness, 78\% identify as non-White or Hispanic. Like families, unaccompanied youth experiencing homelessness are more likely to be Black, more likely to be lesbian, gay, bisexual, and/or transgender, or more likely to have not completed high school'. COVID-19 infections and correlated mortality are significantly higher among homeless people of color (Coughlin et al., 2020).

According to Baral et al. (2021, p. 926), the 'circumstance of homelessness intersects with issues of racialization and other forms of marginalization and colonialism.' Moreover, 'migrants and refugees are often stigmatized and unjustly discriminated against for spreading disease and such unacceptable attitudes further risk wider public health outcomes, including for host populations, since refugees and migrants could be fearful to seek treatment or disclose symptoms' (Kluge et al., 2020 , p. 1239). These findings are consistent with refugees and migrants, including those experiencing homelessness and sleeping rough, reporting increasing discrimination (WHO, 2020). 
Another finding is that '(a)mong individuals who are experiencing homelessness and have substance use disorders, the added stress imposed by the closures of related services may contribute to increased alcohol or drug use and high rates of substance-related morbidity or mortality' (Perri et al., 2020, p. E717). Irregular drug use may result from physical distancing obligations, closed supervised injection facilities, or substance supply shortages. Consequences may include decreased substance tolerance, infection, or overdose. The situation of homelessness in intersection with women, girls, and gender-diverse individuals often forces them to engage in sex work or survival sex to maintain housing or avoid domestic violence. Due to COVID-19-related restrictions, e. g., physical distancing obligations, such activities are prohibited, and individuals may suffer income losses. Therefore, intersecting factors like mental or substance use disorders and sex work can provoke difficulties in individuals in coping with pandemic-specific protocols (Perri et al., 2020). Moreover, during the pandemic, the risk of women and gender-diverse people becoming victims of domestic violence may be higher (Perri et al., 2020). 'Migrant women are likely more exposed to sexual violence, abuse and trafficking, as well as risks related to pregnancy and childbirth' (WHO, 2020, p. 2). Many refugees and migrants have a higher prevalence of noncommunicable diseases. In addition, this group experience challenges in accessing health services when suffering from a chronic condition. Those affected by non-communicable diseases 'may experience an interruption in their care when they move without medicines or health records' (WHO, 2020, p. 2).

\section{Berlin situation}

\section{Municipal emergency assistance services for people experiencing homelessness}

Berlin's municipal emergency housing assistance is separated into two different main categories (see Fig. 1). Regular care includes preventive measures and reintegration assistance aimed at people at immediate risk of homelessness due to their circumstances. The second category, referred to as low-threshold services, contains measures aimed at people who are already facing homelessness and temporarily sleep rough on the streets. In this context, the term low threshold signals that assistance services are non-bureaucratic, independent of authorities, and without a needs assessment (SenIAS, 2019, September 3). The system is hierarchized into four care structures, which will be elaborated below.

First, benefits under Social Code (SGB II and XII) and regulatory accommodation form the regular care, whereby regulatory accommodation is not regarded as a direct part of the social welfare assistance system (SenIAS, 2019, September 3). Under § 67 of the Social Code XII, people whose special living conditions are associated with social difficulties are to be granted assistance to overcome these difficulties. Thus, the eligibility criteria and the initial situations for receiving assistance depend on poor living conditions, simultaneous social difficulties, and a lack of or insufficient skills and competencies of those affected to resolve this complex situation successfully (Gerull, Merckens \& Dubrow, 2009).

Second, the regulatory accommodation is part of the regular care and organized by the district offices. The accommodations provided are subject to a minimum standard. In addition, some districts have their own facilities. If there is no capacity, the district uses other accommodations such as hostels or similar. The responsible district office assigns the homeless person, including the household members, a free place to stay. Social welfare gives a homeless person every opportunity to overcome homelessness (SenIAS, 2019, September 3). 


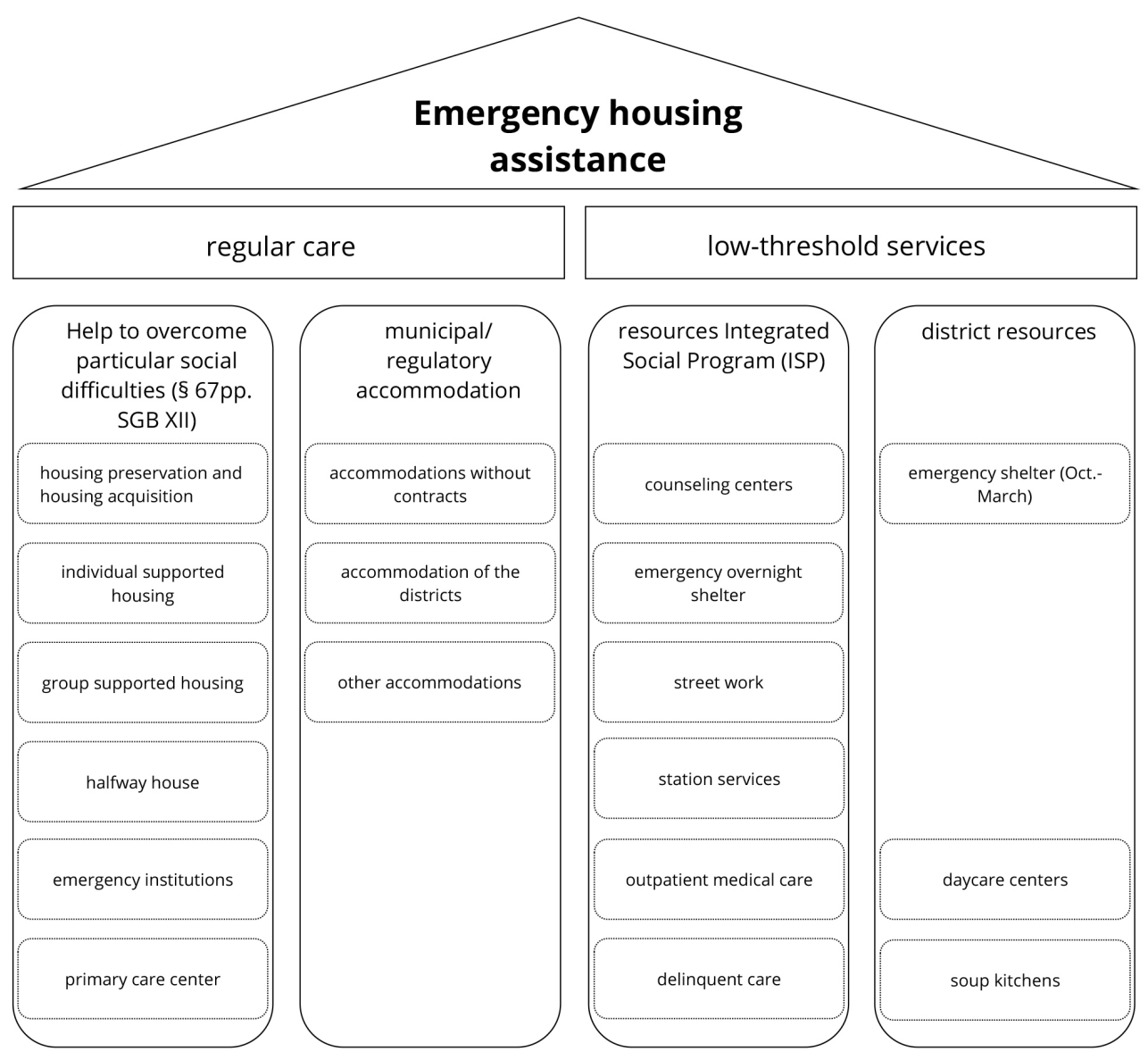

Figure 1. Emergency housing assistance in Berlin Source: based on SenIAS (2019, September 3).

Third, within the Integrated Social Program, Kältehilfe, and homeless day centers, funding is provided for low-threshold facilities or services below the level of regular care. In the Integrated Social Program (ISP), nine providers with 15 counseling, support, and care services for homeless and delinquent people are funded in six different service areas (SenIAS, 2019, September 3).

Four, the district's services, such as Kältehilfe and the homeless daycare centers, are funded by the respective local district. Some districts fund daycare centers for homeless people/meeting places predominantly for people living on the street. The daycare centers provide a low-threshold place to stay, and thus they supply and reach people who would otherwise have little access. The services offered by church congregations and associations are also characterized by a high commitment from volunteers and donations (SenIAS, 2019, September 3). 


\section{Interdependence of levels and actors of assistance services for people experiencing homelessness}

The Senate Departments and district offices partially cooperate with social institutions and non-governmental organizations to provide services on different levels of support to people experiencing homelessness.

Berlin City Mission is a non-profit organization primarily financed by donations and grants and income generated by subsidiaries (BS, 2012). The Mission was founded in 1877 and referred to the Gospel. In addition to providing the necessities of life for the homeless, the aim is counseling and support on the way back to a secure home of one's own (BS, 2021). Since 2018 Berlin City Mission has been running a Clearinghouse for people without health insurance or with insufficient health insurance, this Project is funded by the Berlin Senate (Skzl, 2020, July 21).

Kältehilfe was established in 1989 by Berlin-based church congregations, welfare associations, and the Senate Department for Integration, Labor and Social Affairs to provide non-bureaucratic overnight shelter during the winter for people experiencing homelessness (SenIAS, 2020a, December 15, 2021). Numerous church congregations, associations, and initiatives participate with their own offers, such as night-time cafés, soup kitchens, and meeting places to prevent people without shelter from having to freeze to death. The districts share the financing. GEBEWO ${ }^{1}$ also maintains a coordination Office, the Kältehilfe helpline, and a website. The Senate Department for Integration, Labor and Social Affairs finances the Kältehilfe helpline within the framework of the Integrated Social Program (SenIAS, 2021). Another task of the Senate and the districts is determining the number of emergency sleeping places to be provided citywide (SenIAS, 2019, September 3).

GEBEWO is a non-profit limited liability company founded in 1994. It operates various facilities with assistance specialized in women, emergency housing, and integration. For some of these facilities, there is a legal obligation under $\S 75 \mathrm{i}$. For some of these facilities, there are service agreements with the State of Berlin or other services, cooperation, or grant agreements following $\S 67 \mathrm{ff}$ or $\S 53$ of the Social Code XII (GEBEWO, 2021).

Berliner Obdachlosenhilfe e. $V$. is a non-profit association that was founded in 2013. The association organizes several tours a week to support homeless and needy people. That means, the supporters go to different places in Berlin and provide food, meals, drinks, clothes, sleeping bags, and sleeping mats to people experiencing homelessness. The meals consist of donated food. In addition, there are supporting restaurants and hotels that prepare meals. The association also receives clothes, sleeping bags, and sleeping mats as donations or bought from donations. Furthermore, the association provides information about free health care, emergency shelters, soup kitchens, rehab facilities, psychiatric clinics, and other helping institutions (BO, 2021a, February 6).

\section{Research design}

The paper examines selected press releases of the Berlin Senate Departments published on the press portal of Berlin between March 2020 and April 2021. The focus was on press releases with thematic context to the analysis categories listed below. The resulting data corpus comprises press releases $(n=42)$ issued by the Senate Department for Integration, Labor and Social Affairs, Senate Department for Urban Development and Housing, Senate Chancellery, and various district offices (see Annex 1 for details).

\footnotetext{
${ }^{1}$ Non-Profit Organization for the Care of the Homeless (in German: Gemeinnützige Gesellschaft zur Betreuung Wohnungsloser $\mathrm{mbH}$ ).
} 
The selected press releases are evaluated in a Qualitative Content Analysis following Mayring (2015, p. 48). According to Mayring, the 'embedding of the material in the communication context' is required, which is done in the presentation of the results insofar as text sequences can be identified by the name of the publishing institution, the year of publication, and the number of the press release. Through this proceeding, the analysis achieves intersubjectivity. In addition, the communication context is reflected in the limitations below. The 'categories at the heart of the analysis (Mayring, 2015, p. 49) 'providing and expanding shelter', 'emergency responses concerning refugees', 'tenant protection', 'preventive care and treatment', 'nutrition', and 'repression on people experiencing homelessness' were postulated inductively.

\section{Presentation of material and limitations}

The press releases can be interpreted as accountability statements of the Senate Departments, in which the population is regularly informed about projects, work steps, and progress. Some of the documents contain statistical information, such as the number of emergency overnight shelters available in the previous week and their average utilization figures. Repeatedly, the press releases emphasize both cross-administrative cooperation between Senate Departments and district offices.

However, critically considering the communication context following Flick (2019), press releases can also be read as narratives. The rationalities and socialization processes of actors might shape press releases, only depict selective sections of reality, and provide expediently oriented content in the interest of the publishing bodies. With that in mind, one must assume that events, facts, etc., which could be perceived as unfavorable by the addressees of the press releases, are not presented or glossed over.

\section{Results}

\section{Emergency responses to homelessness regarding COVID-19 in Berlin}

With the beginning of the COVID-19 pandemic in the Federal Republic of Germany and especially with the shutdown in Berlin from March 23, 2020, parts of municipal emergency assistance services for homeless people have broken away. The Berlin Senate, in collaboration with Senate Departments, district offices, and social services, has taken measures to protect people experiencing homelessness and people who might lose housing.

The paper's key results are identifying strategies, which add up from the Senate's accumulated individual measures, steps, and actions. Within this framework, authorities provided and expanded shelters, took steps for preventive care and treatment, and implemented tenant protection. In detail, the findings show that the supply of emergency overnight shelter provided in the winter period 2020/2021 might have met the emerged demand. However, the results also show actions by the Senate concerning emergency responses to refugees, nutrition, and the repression of people experiencing homelessness.

The findings also indicate that intersectionality plays a role in the strategic approach of the Senate. Some measures are gender or disability sensitive, some are multilingual.

Aside from that, the findings highlight the ambiguities of emergency responses concerning people experiencing homelessness regarding COVID-19. On the one hand, measures have brought about significant quantitative and qualitative improvements in the care and support of people experiencing homelessness. On the other hand, implementing some actions has also resulted in losing freedom, restrictions, and reprisals. 
Finally, the findings also show that protecting people experiencing homelessness represents a surmountable challenge for municipalities. Essential points for this are political will, the collaboration of many actors on different levels, and creativity. In a sense, political will is the critical factor that enables financial and bureaucratic leeway. The interaction of small-scale initiatives, the work of voluntary helpers, and the structures and expertise of governmental and non-governmental organizations enable resilient aid networks and care. Finally, the exploration and testing of new approaches is a key to overcoming the challenges of the crisis.

Figure 2 shows schematically Senate administrations involved in strategic emergency responses and related measures in detail. In this context, the sum of individual efforts concerning one topic can be interpreted as a strategy in a superordinate meaning. For example, the Senate Department for Health, Care and Equality played a crucial role in mobile vaccinations. The Senate Department for Integration, Labor and Social Affairs was involved in all measures to provide and expand shelter. Moreover, the same Department realized SARS-CoV-2 virus prevention and quarantined and treated infected persons. The Senate Department for Urban Development and Housing implemented measures for tenant protection. The figure simplifies and does not consider all the efforts and contributions of municipal services, NGOs, and voluntary supporters.

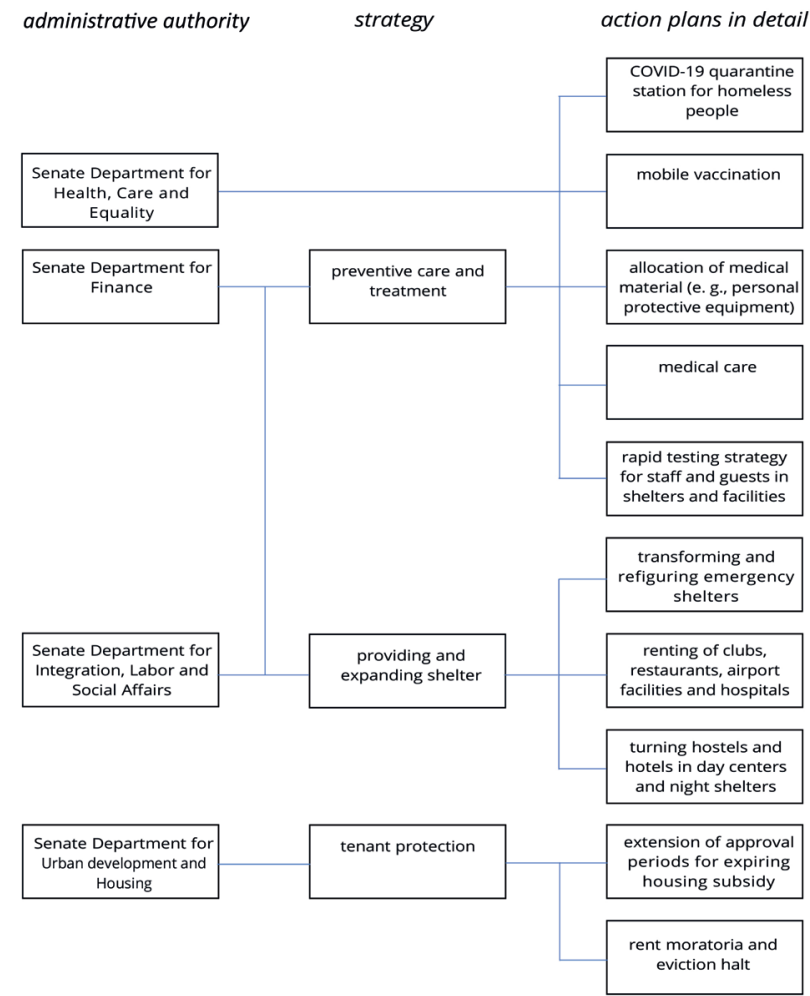

Figure 2. Strategies and action plans of the Berlin Senate concerning homelessness

Table 1 features a timeline of emergency responses in Berlin deduced from the empiric material. The most crucial turning points in the pandemic for the Berlin study area are shown and decisive developments concerning homelessness care. A chronological classification takes place, and the corresponding implementing authority is named. 
Table 1. Timeline of emergency responses in Berlin (surveyed between March 2020 and April 2021)

\begin{tabular}{|c|c|c|}
\hline Month & Emergency responses & Authority / institution \\
\hline \multicolumn{3}{|c|}{2020} \\
\hline \multirow[t]{2}{*}{ March } & $\begin{array}{l}\text { first COVID-19 cases in Berlin } \\
\text { first emergency responses regarding people } \\
\text { experiencing homelessness and COVID-19 }\end{array}$ & $\begin{array}{c}\text { Senate Department for Integration, Labor and } \\
\text { Social Affairs }\end{array}$ \\
\hline & first shutdown, social and physical distancing & Berlin Senate \\
\hline April & $\begin{array}{l}\text { opening of the first COVID-19 quarantine } \\
\text { station for people experiencing homelessness }\end{array}$ & $\begin{array}{c}\text { Senate Department for Finance, } \\
\text { Senate Department for Integration, Labor and } \\
\text { Social Affairs, } \\
\text { District Office Mitte, } \\
\text { Berlin City Mission }\end{array}$ \\
\hline October & $\begin{array}{l}\text { offers of Kältehilfe start and are } \\
\text { expanded successively }\end{array}$ & $\begin{array}{l}\text { Senate Department for Integration, Labor and } \\
\text { Social Affairs, district offices }\end{array}$ \\
\hline November & $\begin{array}{l}\text { rapid testing strategy for people experiencing } \\
\text { homeless }\end{array}$ & $\begin{array}{c}\text { Senate Department for Integration, Labor and } \\
\text { Social Affairs }\end{array}$ \\
\hline December & second shutdown & Berlin Senate \\
\hline \multicolumn{3}{|c|}{2021} \\
\hline February & $\begin{array}{c}\text { eviction of encampment at Rummelsburger } \\
\text { Bucht }\end{array}$ & $\begin{array}{l}\text { District Office Lichtenberg, Senate } \\
\text { Department for Finance, Senate Department } \\
\text { for Integration, Labor and Social Affairs, }\end{array}$ \\
\hline April & $\begin{array}{c}\text { adoption of the Infection Protection Act } \\
\text { Berlin Senate starts vaccinating people } \\
\text { experiencing homelessness }\end{array}$ & $\begin{array}{c}\text { German Federal Law } \\
\text { Senate Department for Integration, Labor and } \\
\text { Social Affairs } \\
\text { Senate Department for Health, Care and } \\
\text { Equality }\end{array}$ \\
\hline
\end{tabular}

\section{Providing and expanding shelter}

Due to the pandemic-related closure of numerous supportive services, including emergency overnight services, hygiene protocols that minimize occupancy rates in remaining facilities, and severe restrictions in public spaces, the day-to-day life of homeless people has drastically worsened. Therefore, the Senate recommends strengthening protections for the homeless, for the duration of the COVID-19 pandemic. The first steps are expanding the capacity of an emergency shelter and refiguring a facility into a day shelter (SenIAS, 2020, press release 911194, 925970).

The implementation of the hygiene protocols in the shelters requires creativity from the authorities. For example, the minimum distance between beds should be $2 \mathrm{~m}$ to avoid infection. In one case, the authorities rented three additional floors and equipped them with beds. However, that shelter also has options to house COVID-19 infected individuals in isolation. In addition, catering, psychosocial and socio-educational service assistance is also being offered, where guests can check prospects for permanent housing, so-called exit strategies, and potential claims for social subsidies. Medical professional rounds are offered regularly (SenIAS, 2020, press release 927732, 967896, 932293). In this regard, a centrally located temporary day center takes over functions that were decentralized in various facilities before the COVID-19 pandemic. Local and functional centralization could be interpreted as an improvement because it requires only one way from the recipients of the offered services. At the same time, the use of several services by the same person is more likely due to their lower-threshold availability. In other words, when someone is already in the restaurant to eat, it is more likely that one will also take advantage of counseling or medical advice. 
In these initial efforts, one point becomes clear that will run through the rest of the period under review, namely the benefits of collaborative practice. In this case, the District Office Pankow and GEBEWO determine the cooperation.

In May, in cooperation with the social agencies, the Senate keeps the number of places in emergency shelters constant. A shelter with 108 places is newly opened, while another one closes (SenIAS, 2020, press release 930275, 967896).

As of October 1, 2020, the Kältehilfe starts as planned with an initial capacity of 500 emergency overnight places under the responsibility of the Berlin districts, which is successively expanded to about 1,000 places and reached the capacities of previous years. In winter 2019/2020, up to 1,150 emergency overnight places were offered in the seven months of the Kältehilfe period (October-April), with an average of 981 emergency overnight places available (SenIAS, 2020, press release 998963, 977704).

As of November 1, 2020, Kältehilfe provides 1,000 emergency overnight places to people experiencing homelessness (SenIAS, 2020, press release 1011263). In this period of Kältehilfe, for the first time, three hostels, in sum, offer 200 emergency overnight places, in addition to other facilities. Funding for the higher costs of accommodation such as staff and hygiene equipment could be secured with the support of the Senate Department for Finance (SenIAS, 2020, press release 1011263). Taking over the funding emphasizes the political will to create the structures needed to provide housing for people experiencing homelessness.

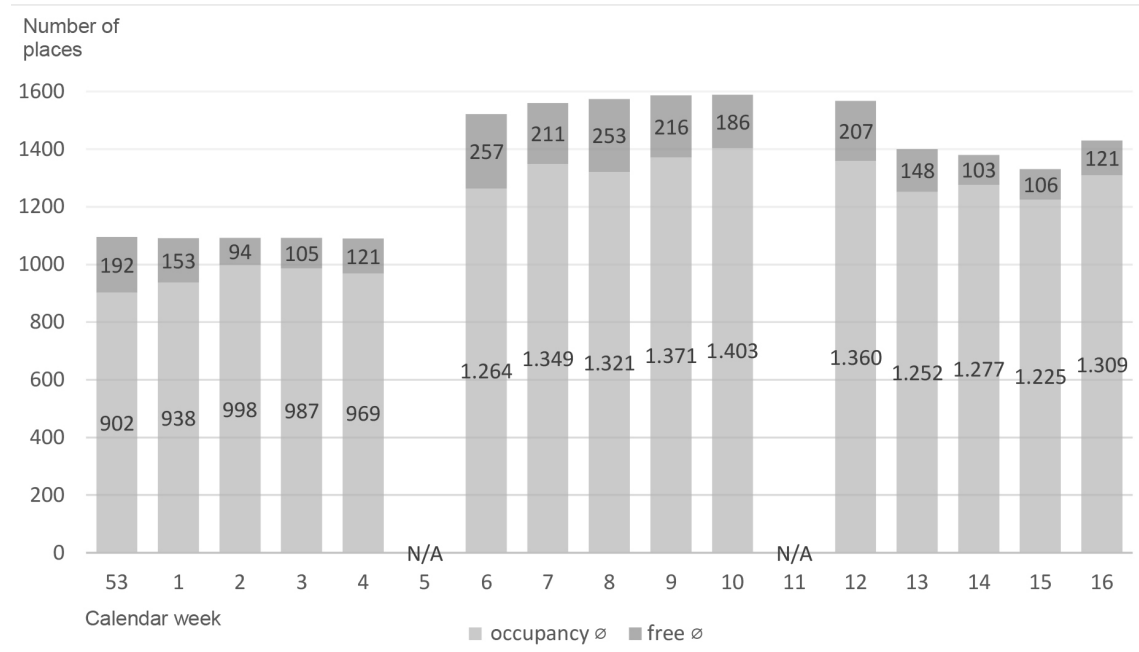

Figure 3. Capacity and occupancy in emergency overnight stays (Kältehilfe) in winter 2020/2021

Figure 3 shows the capacities of emergency overnight places of the Kältehilfe in the calendar weeks 53, 2020 to 16, 2021. The occupancy is shown in light grey, while the remaining free places are colored in dark grey at the top of the columns. At the beginning of 2021 , the city is repeatedly increasing the total amount of places due to the dramatic weather conditions. It is striking that many places remain unused, at least on a weekly average; these concerns 165 emergency overnight places on average for the whole period of Kältehilfe 2020/2021. The Senate Department for Integration, Labor and Social Affairs weekly publishes figures of the offered capacity and occupancy of emergency overnight places by the Kältehilfe (SenIAS, 2021, press release 1036775, 1039361, 1042431, 1045120, 1048199, 1053923, 1056646, 1070974, 1072537, 1074848, 1077205, 1079819). 


\section{Places in emergency overnight shelters in winter 2020-2021 in Berlin}

Implementing the new restrictions set out in the Second SARS-CoV-2 Infection Control Measures Ordinance, which came into effect in Berlin on December 16, 2020, further reduced the capacity of daytime services. This step limited the number of places in day centers and soup kitchens.

Originally envisioned measures are not sufficient, and so the development falls short of the need. For example, the restaurant Hofbräu Berlin is being refigured as a day center, and the number of permitted guests gradually increases. Guests can get multilingual counseling, placement, and employment services from GEBEWO staff. Moreover, a medical service is available (SenIAS, 2020 , press release 1024744,1030788 ). In this temporary day center, too, a centralized bundling of formerly decentralized competencies is taking place.

In December 2020, authorities provide additional facilities or expand existing ones. In one example, the capacity increases from 16 up to 120 quarantine places (SenIAS, 2020, press release 1024744).

The findings also indicate that intersectionality plays a role in the strategic approach of the Senate, even if only a marginal one. First, homelessness in intersection with female gender is considered by emergency assistance. In that, a shelter with 30 places is opened, which is aimed exclusively at women (SenIAS, 2020, press release 1024744). If one looks at the low number in comparison to the total number of emergency overnight accommodations, the need to expand the range of gender-sensitive offers also becomes apparent. Second, some services are accessible to the needs of people where homelessness and disability intersect. Thus, two of the facilities created are barrier-free, and people in wheelchairs have access. Third, many expanded and refigured shelters focus on language access for migrants and refugees and provide multilingual offers (SenIAS, 2020, press release 1030788).

In February 2021, authorities expand the number of shelters and refigure the existing ones significantly. As a reason, different municipal authorities refer to the forecasted cold front. The number of people experiencing homelessness has not increased, but the number of those who might freeze to death when sleeping rough is now higher. Correspondingly, five buses with social workers are on the road in outreach work to support and pick up rough sleepers (SenIAS, 2021, press release 1049734; BA Steglitz-Zehlendorf, 2021, press release 1051151).

The supply of emergency overnight places significantly expanded in the same month, reaching an unprecedented high of 1,426 places in February. In particular, 624 of the places are provided by daytime and nighttime facilities offering meals and social counseling. The renting of seven hostels also represents a climax (SenIAS, 2021, press release 1051043).

As part of this expansion, authorities are willing and creative again to create new spaces. This time, the senate succeeds by going beyond conventional solutions, and venues that had to close due to hygiene protocols offer increased potential. A club becomes a warm-up venue for 80 people, the heated hangar at the former airport opens its doors to 100 rough sleepers, and a 24/7 shelter with up to 200 places is opened in a former mental hospital (SenIAS, 2021, press release $1051043,1049734)$. This procedure also requires an enormous financial effort, which should not go unnoticed.

However, as announced, the temporary additional-created offers end on April 30, 2021. The expiration of the measures shows that the city acts accordingly, especially when there is an immediate threat to the lives of people experiencing homelessness. As temperatures rise, this danger decreases. Nevertheless, the need for emergency shelters remains constant to prevent people from sleeping rough on the street. 


\section{Emergency responses concerning refugees}

Since the end of April 2020, homeless refugees in quarantine, who were previously housed in shared accommodation, were isolated in the so-called Tempohome. The Tempohome is a container village with an accommodation capacity of up to 300 people. The State Office for Refugee Affairs (LAF) requisitioned this accommodation based on the General Security and Order Act. Logistics include full boarding of the quarantined, providing daily necessities such as hygiene items supplied from outside, and all transportation to the shelter. If hospitalization is necessary, sick individuals are transported by doctors and medical professionals to hospitals (SenIAS, 2020, press release 913584). In this case, the implementation of cohorting by public authorities is an ambivalent measure. Cohorting (group persons who already got infected, might be infected, or are not infected with SARS-CoV-2) is a spatialstrategic approach, which has emerged internationally as an efficacious measure to curb transmission of COVID-19. On the one hand, it represents a measure of care where infected individuals are treated and observed. On the other hand, quarantine is also a preventive measure that prevents transmission among the host population. The decentralized isolation of refugees is a highly questionable measure and must be scrutinized concerning the increasing discrimination outlined the beginning, in which migrants are held responsible for spreading disease.

However, refugees themselves also support particularly vulnerable social groups in coping with the COVID-19 crisis, for example, by providing support for homeless people in a cooperative project between GoVolunteer and the Senate Chancellery. Civic engagement goes much further as refugees offer help with translations, relieve medical staff, or are on duty as paramedics (Skzl, 2020, press release 920740). This project shows the importance of collaborative practices and the essential importance of even small-scale initiatives. In addition, an allocation of competencies takes place here, which municipal actors would presumably not be able to implement in a targeted manner on the same scale, e.g., linguistic access. It is also evident here that institutionalized actors depend on support from civil society to provide holistic assistance.

\section{Tenant protection}

Since April 2020, the Senate Department for Urban Development and Housing has been beginning to intervene preventively by communicating to the districts to automatically extend the approval periods of expiring housing subsidy approvals for six additional months (SenSW, 2020, press release 6873). In addition, the communal housing associations are required to maintain the previous solidarity-based protection measures unchanged. This means that a moratorium on rent arrears comes into effect continuously or individually, and amicable solutions are agreed upon. Accordingly, no termination notices are issued due to payment arrears and eviction titles for rented apartments are not enforced (Skzl, 2020, press release 1033923). Furthermore, no rent increases affect residential and commercial tenants of the communal housing associations until the end of 2020 (SenSW, 2020, press release 997842). In September, the Berlin Senate decided to prolong the measures to improve tenant protection and prevent housing losses, in the first instance until the end of 2020 (SenSW, 2020, press release 6967), later until the end of March 2021. During this period, the Senate demanded private landlords to adapt their measures (Skzl, 2020, press release 1033923).

With these measures, the Senate is preventing an increase in those experiencing homelessness or sleeping rough. Nonetheless, the rent moratoriums, unenforced eviction orders, and approved housing subsidies are temporary strategies that delay, rather than prevent, precarious housing situations. The underlying problems of the tight rental market and low-wage employment remain unaffected. 


\section{Preventive care and treatment}

In May 2020, the first COVID-19 quarantine station in Germany specifically for homeless people is put into operation on the campus of the Berlin City Mission (SenIAS, 2020, press release 930275). The quarantine station is a cooperation of District Office Mitte, Berlin City Mission, Senate Department for Integration, Labor and Social Affairs, and Senate Department for Finance. Up to 16 people suffering from COVID-19 can be housed, cared for, and supported in a quarantine environment (BA Mitte, 2020, press release 942001). The implementation of cohorting by public authorities superficially serves the care of the infected. Still, authorities may intend to protect the urban population from further transmission. However, this argument is extendable to all other epidemiological health care measures listed below.

From November 2020, a so-called rapid testing strategy for people experiencing homeless is initiated, which provides for 46,500 tests to be carried out until March 2021. The designated goal is to test guests of services once a day and staff once a week. In six facilities, the tests can be carried out by medically trained staff. For this purpose, personal protective equipment (PPE) is distributed, i.e., FFP2 masks, goggles/visors, gowns, gloves, and disinfectants (SenIAS, 2020, press release 1024744).

In December 2020, there was a COVID-19 outbreak in a shelter with eleven infected individuals. The response of the authorities foresees the cohorting of the affected persons. Infected individuals are quarantined in an air dome while category I contacts are isolated in a hostel and cared for in collaboration of district office and Berlin City Mission (BA Friedrichshain-Kreuzberg, 2020, press release 1033034).

At the end of February 2021, the Berlin Senate eventually offered homeless people the opportunity to be vaccinated. The federal government's COVID-19 vaccination regulation categorizes homeless people as Group 2 (high priority) in the vaccination order. The reason for this is the vulnerability of this group of people, given their living conditions. At the same time, the offer applies to the staff in the corresponding facilities. The Senate Department for Integration, Labor and Social Affairs realizes the Berlin-wide organization of this step in cooperation with social agencies and facilities for the homeless and the Senate Department for Health, Care and Equality. Vaccination occurs in so-called 'vaccination islands' set up in facilities of assistance services. The injection is carried out by medically trained staff, providing multilingual vaccination counseling and accompanying care (SenIAS, 2021, press release 1064433). Due to the nationwide halt of vaccinations with the AstraZeneca vaccine, the start of the vaccination campaign for homeless people in Berlin postpones, vaccinations finally start on March 22, 2021 (SenIAS, 2021, press release 1065050; SenIAS, 2021, press release 1068518). Since April 27, mobile vaccination teams have been on duty to vaccinate people experiencing homelessness. For this purpose, the Senate Department for Integration, Labor and Social Affairs provides up to 3,000 doses of the Johnson \& Johnson vaccine. For the time being, the vaccinations are being carried out in more than 20 selected facilities of assistance services (SenIAS, 2021, press release 1079541).

As of March 31, 2021, the regulations in force in Berlin are being further tightened based on the stipulations of the Berlin Senate in the 2nd Infection Protection Measures Ordinance. According to this, an FFP2 mask requirement is basically effective in enclosed spaces, which must be implemented, for example, in public transport, in medical practices, hospitals and care facilities, as well as in retail outlets (SenIAS, 2021, press release 1070660). For this reason, 1.6 million FFP2 masks are allocated in district facilities, homeless assistance facilities, and facilities of the State Office for Refugee Affairs (SenIAS, 2021, press release 1070660). 
The rapid testing strategy, vaccinations, and the allocation of medical material are cost-intensive measures that reflect the city government's interest in achieving successes in prevention that go beyond symbolic politics.

\section{Nutrition}

Providing food for people experiencing homelessness is a challenging task for Berlin, especially during a worldwide pandemic. The Senate is dependent on cooperation with numerous and diverse actors. Providing food is also a logistical challenge, and the Senate can achieve this through a broad network of organizations and supporters. For instance, members of the refugee network 'Be an Angel e. V.' have been cooking 450 hot meals every day since the end of December 2020 in the restaurant Kreuzberger Himmel. In parallel, 450 lunch packages were prepared in the adjacent hall of the Catholic parish of St. Boniface. The portions are delivered every lunchtime to social institutions throughout the city. Berlin is funding the aid project until March 2021 (SenIAS, 2020, press release 1033597).

Over the pandemic, some different places and initiatives have worked to provide food for people experiencing homelessness. These places include restaurants, shelters, clubs, and the heated hangar at the former Tempelhof Airport (SenIAS, 2020, press release 1030788, 1024744, 1051043). Nevertheless, this challenge is dependent on civil society support. In the district Pankow, a social agency cooperating with Berlin City Mission provides coronavirus information in multiple languages, fresh food, hygiene items to people experiencing homelessness. According to the district office, support is needed from the civic society (BA Pankow, 2020, press release 921677).

\section{Repression on people experiencing homelessness}

Some of the measures outlined above have improved services to homeless people or at least maintained the status quo. However, the Senate and district offices, as well as the federal government, have also taken actions that have led to increased reprisals and sanctions.

There are several homeless encampments in Berlin, the largest of which, consisting of tents and alternative housing, is located at Rummelsburger Bucht and whose population was estimated at 81 in 2020 (Berlin.de, 2021, February 6). This very camp was evacuated on the night of February 6,2021 , at the behest of the responsible District Office Lichtenberg. The procedure was flanked by employees of the German Red Cross, the Fire Department, the police, the technical support service, and local social services (BA Lichtenberg, 2021, press release 1049876). The Berlin public transportation services provided buses for the transport to the temporary shelter. The District Office Lichtenberg and the Senate Department for Integration, Labor and Social Affairs insisted on the danger to the residents' lives due to the announced extreme weather conditions as the primary motive for the short-term intervention (BA Lichtenberg, 2021, press release 1049876). For that night, camp residents have been offered overnight sleeping places in an air dome. Social and left-wing associations sharply criticize the actions of the district. The Berliner Obdachlosenhilfe e.V. (BO, 2021b) criticizes that no long-term perspective is offered and quotes a police officer with the words 'the camp will be flattened tomorrow'. Particularly controversial about the eviction is that the camp is located on private land of various owners (BA Lichtenberg, 2021, press release 1049876), and that there is a development plan for the area, which includes building apartments and an underwater museum (Berlin.de, 2021). Although the camp residents can collect their belongings, the camp is dismantled in the following days, and the area is bulldozed and leveled for construction (Angeloudis, 2021, February 9). 
This incident shows where homelessness and migrant status intersect. Reportedly, a large proportion of the residents were migrants and refugees, many of them Sinti and Roma. Lack of language skills was highly problematic in several respects. The lack of communication by the authorities in the run-up to the eviction has further increased mistrust here. However, social services also criticized the communication during the eviction itself, which resulted in many residents fleeing (Berlin.de, 2021, February 6; Angeloudis, 2021, February 9). In addition, the camp had offered people the opportunity to escape the system and live as hidden homeless. Thus, some of the residents had jobs but could not afford an apartment (Häde \& Breden, 2021, February 11).

Another incident that had severe consequences for people experiencing homelessness was the takeover of the pandemic regulations by the federal government on April 25, 2021. The federal government intended to eliminate the previous politically irreconcilable differences between the federal states in dealing with the pandemic. As a result, for homeless people, this undermines the Senate's state ordinance which allowed groups of up to ten people. Thus, the upper limit of persons in public space regulated in paragraph 3 explicitly did not apply to homeless people and related services (Skzl, 2021, April 27, paragraph 4/5, 4/6). 'This regulation applied around the clock allowed for both shared night camps and social contact during the day' (Salmen, 2021; translated by the author). At the same time, an exception allowed rough sleepers to stay in public spaces at night which was appropriate in the absence of accommodation and shelter. The federal regulation does not provide for such exceptions. Thus, Article 1.1 states: 'private gatherings in public or private spaces are permitted if they are attended by no more than the members of one household and one other person.' Article 1.2 prohibits 'the stay of persons outside a dwelling or accommodation (...) from 10 p.m. until five a.m. of the following day' (BMG, 2021, April 22, translated by the author). The regulations took effect based on the rate of COVID-19 cases per day per 100,000 inhabitants averaged over seven days. This procedure criminalizes homeless people who either live rough or in alternative housing and have formed shelter communities. 'In purely legal terms, the federal government has weakened the position of homeless people in Berlin through the new Infection Protection Act' (Salmen, 2021; translated by the author).

\section{Discussion}

Several studies point to the collaborative practice between governmental and civil organizations in responses to homelessness regarding COVID-19. Collaborative planning between organizations advantaged the sharing of resources, medical material, and information (Baral et al., 2021). Benavides \& Nukpezah (2020, p. 652) stressed the importance of coordination between different levels of government in responding to homelessness, e.g. 'federal, state, and local government as well as nonprofits, and community and neighborhood organizations.' For instance, local organizations can best identify local needs. Also, it is not the Berlin Senate alone that has taken on the challenges, but the cooperative collaboration of municipal institutions and NGOs. While the Senate Department for Integration, Labor and Social Affairs and the Senate Department for Finance took over the financial support, e.g. in the provision of temporary shelters, social services such as Kältehilfe and GEBEWO organized the operation of the shelters. Nonetheless, support from the civic society was needed in Berlin, e.g., in providing food for people experiencing homelessness.

'Advocates have suggested solutions such as emergency rental assistance, eviction prevention assistance, and a moratorium on evictions and foreclosures' (Coughlin et al., 2020, p. 9). These findings are consistent as in Berlin rent moratoria and eviction halt came into play. However, com- 
pared to private landlords, the communal housing associations were much more willing to act of courtesy in this regard.

Fuchs et al. (2021) describe hotels in the U.S. that isolate or quarantine people experiencing homelessness with alcohol and substance abuse disorders. Substitution and donated alcoholic beverages are used to try to keep the conditions of these people reasonably stable. These findings are consistent with practice at the quarantine station for people experiencing homelessness in Berlin. People suffering from an alcohol disorder can get the alcohol level in their blood recorded, and then the demand they need is provided (Nehls, 2021, February 2).

Several studies emphasize the importance of emotional services in coping with the COVID-19 disease to address individuals experiencing homelessness (Perri et al., 2020; Banerjee \& Bhattacharya, 2021; Nunes et al., 2021). As Dotson, Ciarocco and Koh (2020, p. 1006) stress, 'the mental health needs of people who are homeless during disasters have received minimal attention'. The sudden closing of social and public facilities and the severance of social relationships can harm the mental health of individuals experiencing homelessness (Perri et al., 2020). In Berlin, the authorities have considered this by providing psychosocial services in at least one expanded shelter. Nonetheless, there is a great need for action in this field so that this aspect should be given considerable attention in future interventions.

The temporality of the interventions remains questionable. With the announced expiration of the rents, the temporary shelters will disappear, and individuals will end up back on the street. In Australia, the additional support and resources deployed during COVID-19 will end when the pandemic is over. This crisis has not caused a shift in homelessness policy, but rather the temporary measures serve as preventive measures to protect public health (Parsell, Clarke \& Kuskoff, 2020). According to Parsell et al., 'homelessness is represented as a risk to both people who are homeless and society writ large' (2020, p. 10). In Berlin, a similar problem arose because the measures implemented were initially temporarily limited. Thus, the expiration of the measures represents a step backward for homeless assistance.

However, the measures described vary widely, and the end of some regulations will mean more freedom to people experiencing homelessness.

In Brazil and India, there are reports of forced displacement by authorities (Lewis, Ram, Sayed \& Aditi, 2020, March 24; Nunes et al., 2021), these findings are consistent with a reported instance in Berlin by removing the largest homeless encampment. Perri et al. (2020) have shown that legislative regulations in the context of COVID-19 often criminalize people experiencing homelessness in their daily lives, e.g. when standing in line or being in public is legally prohibited. In Berlin, legislative regulations such as the Infection Protection Act and the Federal COVID-19 Measures Act had a restrictive effect against people experiencing homelessness, too.

\section{Conclusion}

The Berlin Senate undertook explicit actions and strategies to protect people experiencing homelessness. The main strategies were to provide and expand shelter, to realize preventive care and treatment, and to put tenant protection in place. Explicit actions regarding the first strategy were to rent a variety of venues, including hotels, hostels, clubs, restaurants, airport facilities, and hospital rooms, and expand and refigure existing shelters. The second strategy was realized by allocating medical material, isolating different groups, and finally offering vaccination. Third, the tenant protection was to implement rent moratoria and eviction halt, at least to tenants of communal housing associations. 
Furthermore, the question was to what extent Senate measures and interventions at the onset of the COVID-19 pandemic address the emergent need for homeless assistance services in Berlin. The results show that the supply of emergency overnight places provided in the winter period between October 2020 and April 2021 might have met the emerged demand, which can be deduced from the fact that, on average, 165 emergency overnight places remained unused.

The COVID-19 pandemic creates an unprecedented situation that calls for the special protection of people experiencing homelessness and thus requires concepts for action and solutions that obligate the Berlin Senate. Strategically, the Senate is focusing on intensifying the protection of homeless people by increasing emergency capacities and creating alternatives despite numerous closures and drastic restrictions on regular assistance. Some of the Senate's interventions described above bring about quantitative and qualitative improvements in emergency assistance compared to previous years. Hence, the potential of affirmative municipal policy in homeless assistance becomes visible, e.g. in the consistency and willingness to acquire and appropriate shelters. In opposite, some actions have also resulted in a loss of freedom, restrictions, and reprisals.

Examining emergency responses to people experiencing homelessness regarding COVID-19 has yielded several valuable lessons.

First, the results show that political will can provide necessary shelters to prevent people from sleeping rough. This political will requires overcoming financial and bureaucratic hurdles. In a comparatively short period, the Senate succeeds in developing a supply of emergency overnight accommodations that meets the emergent need. For this purpose, accommodations are rented and acquired and refigured in a short time, resulting in a considerable contingent of places for daytime and nighttime. In this light, however, it can also be observed that there is a significant lack of homeless people housing. This challenge repeatedly requires the acting authorities to redesign existing facilities in terms of their use or to rent real estate. The need for emergency overnight shelters can be met, thus averting the catastrophe for the time being. This time the Senate manages to ensure that no one has to sleep rough, at least in the cold season. However, it is not enough to provide places in emergency shelters; there must be tangible ways out of homelessness. Authorities must create permanent and attractive perspectives for individuals experiencing homelessness, such as Housing First Berlin (HFB, 2019, December 6). The uncompromising and unconditional provision of housing is a central measure of an exit strategy from homelessness. In addition, the perspective must change, and a change from top-down to bottom-up approaches must take place, in which actor-centered solution concepts also become conceivable, for example, the consolidation and formalization of safe place concepts. In this context, the need to protect certain social groups should also be brought further into the focus of measures, for example, the specific requirements of migrants and refugees. To this effect, it also needs creative solutions that think outside the box and offer new possibilities.

Second, creativity and improvisation arise here from unprecedented situations. The COVID-19 crisis has created a space of opportunity for these aspects in Berlin. The authorities show creativity in their choice of accommodations, such as renting a club, a former mental-hospital, or an airport building. This is a salient way of dealing with the city's resources, some of which are closed anyway due to the pandemic. Establishing vaccination islands, i.e., centralized points of contact within shelters, is also a creative strategy that should increase vaccination readiness for people experiencing homelessness and shelter staff.

Third, not the government alone but the cooperative collaboration of municipal institutions and NGOs makes the difference. Thus, engagement and support from civic society can make essential contributions. Many of the structures and support services mentioned above are based on 
complex logistics that can only be achieved through networks of institutional, but also voluntary actors. The food supply alone for people experiencing homelessness is surprisingly complex. From food acquisition, preparation, distribution to appropriate spots and serving, many actors are involved, and planning and execution is extensive. But small-scale civic approaches and initiatives also play an essential role in supporting vulnerable groups.

Finally, the findings also show that homelessness does not have to be an inherent component of metropolitan areas. Instead, cities may be able to protect their most vulnerable groups holistically. The means to do so are as diverse as the people and their needs themselves: a conversation, a meal, a doctor's visit, a shelter, a home.

\section{References}

Angeloudis, E. (2021, February 9). Räumung oder Rettung? Das Obdachlosencamp an der Rummelsburger Bucht. Rundfunk Berlin-Brandenburg. Retrieved from https://www.rbb24.de/politik/beitrag/2021/02/berlin-obdachlose-rummelsburger-bucht raeumung-oder-rettung.html

Annen, P. (2020). Agency auf der Straße. Eine biografietheoretische Studie zu jungen Menschen und ihren Wegen in die Wohnungslosigkeit. Trier-Wiesbaden: Springer VS. https://doi.org/10.1007/9783-658-30762-2_2

BAG W (2019, November 11). Wohnungslosigkeit: Kein Ende in Sicht. BAG Wohnungslosenhilfe stellt aktuelle Schätzung für das Jahr 2018 vor. Bundesarbeitsgemeinschaft Wohnungslosenhilfe e.V. Retrieved from relaunch.bagw.de/de/themen/zahl-der-wohnungslosen/index.html

BAG W (2020, November 6). Zwischen Kältetod und Infektionsgefahr. BAG W: Corona-Pandemie erfordert Ausweitung der Kältehilfe für wohnungslose Menschen. Bundesarbeitsgemeinschaft Wohnungslosenhilfe e.V. Retrieved from https://www.bagw.de/en/neues/news.8220.html

Banerjee, D., \& Bhattacharya, P. (2021). The hidden vulnerability of homelessness in the COVID-19 pandemic: Perspectives from India. International Journal of Social Psychiatry, 67(1), 3-6. https://doi. org/10.1177/0020764020922890

Baral, S., Bond, A., Boozary, A., Bruketa, E., Elmi, N., Freiheit, D., Ghosh, S. M., Goyer, M. E., Orkin, A. M., Patel, J., Richter, T., Robertson, A., Sutherland, C., Svoboda, T., Turnbull, J., Wong, A., \& Zhu, A. (2021). Seeking shelter: Homelessness and COVID-19. FACETS, 6, 925-958. https://doi.org/10.1139/ facets-2021-0004

Benavides, A. D., \& Nukpezah, J. A. (2020). How Local Governments Are Caring for the Homeless During the COVID-19 Pandemic. The American Review of Public Administration, 50(6-7), 650-657. https:// doi.org/10.1177/0275074020942062

Berlin.de (2021, February 6). Obdachlosencamp in Berlin geräumt - Proteste linker Gruppen. Berlin.de Das offizielle Hauptstadtportal. Retrieved from https://www.berlin.de/wetter/nachrichten/6436387-3722621-obdachlosencamp-in-berlin-geraeumt-prote.html

BMG (2021, April 22). Viertes Gesetz zum Schutz der Bevölkerung bei einer epidemischen Lage von nationaler Tragweite. Bundesgesundheitsministerium. Retrieved from https://www.bundesgesundheitsministerium.de/fileadmin/Dateien/3_Downloads/Gesetze_und_Verordnungen/GuV/B/4_BevSchG_BGBL.pdf

BO (2021a, February 6). Kältehilfe oder Zwangsräumung? Wir waren dort und die Antwort ist klar. Berliner Obdachlosenhilfe e.V. Retrieved from https://twitter.com/B_Obdachlosenhi/status $/ 1357884415905521667$

BO (2021b). Über uns. Berliner Obdachlosenhilfe e.V. Retrieved from https://www.berliner-obdachlosenhilfe.de/unser-verein/ueber-uns/

BS (2012). Selbstverpflichtung. Spendenleitlinie der Berliner Stadtmission. Berliner Stadtmission. Retrieved from https://www.berliner-stadtmission.de/wie-sie-helfen-koennen/selbstverpflichtung/ selbstverpflichtung

BS (2021). Wohnen für Wohnungslose. Berliner Stadtmission. Retrieved from https://www.berliner-stadtmission.de/wohnen-fuer-wohnungslose 
Coughlin, C. G., Sandel, M., \& Stewart, A. M. (2020). Homelessness, Children, and COVID-19: A Looming Crisis. Pediatrics. 146(2), 7-9. https://doi.org/10.1542/peds.2020-1408

Dotson, S., Ciarocco, S., \& Koh, K. A. (2020). Disaster psychiatry and homelessness: creating a mental health COVID-19 response. The Lancet Psychiatry, 7(12), 1006-1008. https://doi.org/10.1016/ S2215-0366(20)30343-6

Fitzpatrick, S., Watts, B., \& Sims, R. (2020). Homelessness Monitor England 2020: COVID-19 Crisis Response Briefing. London: Crisis.

Flick, U. (2019). Qualitative Sozialforschung. Eine Einführung (9th edition). Reinbek bei Hamburg: Rororo. Rowohlts Enzyklopädie.

Franke, M. (2015). Obdachlosigkeit in Deutschland: Integrative und inklusive Handlungsstrategien im Bereich der Obdachlosenhilfe. Hamburg: Diplomica Verlag.

Fuchs, J. D., Carter, H. C., Evans, J., Squire, D. G., Imbert, E., Bloome, J., Fann, C., Skotnes, T., Sears, J., Rosenblum, R. P., Moughamian, A., Eveland, J., Reed, A., Borne, D., Lee, M., Rosenthal, M., Jain, V., Bobba, N., Kushel, M., \& Kanzaria, H. K. (2021). Assessment of a Hotel- Based COVID-19 Isolation and Quarantine Strategy for Persons Experiencing Homelessness. JAMA Network Open, 4(3), 1-14. https://doi.org/10.1001/jamanetworkopen.2021.0490

GEBEWO (2021). Über uns. GEBEWO Soziale Dienste Berlin. Retrieved from https://www.gebewo.de/ ueber-uns

Gerull, S., Merckens, M., \& Dubrow, C. (2009). Qualitative Studie zu „Erfolg“ in der Hilfe nach § $67 \mathrm{ff}$. SGB XII. Alice Salomon Hochschule Berlin. pp. 125 (Abschlussbericht). Retrieved from https://www.berlin.de/sen/soziales/_assets/besondere-lebenssituationen/wohnungslose/endbericht_erfolg_67.pdf

Häde, S., \& Breden, S. (2021, February 11). Berlin: Räumung des größten Obdachlosencamps Deutschlands. Y-Kollektiv: Retrieved from https://www.youtube.com/watch?v=5demogZO60c

Haesbaert, R. (2020). Geographische Überlegungen in Zeiten der Pandemie. sublurban . Zeitschrift für kritische Stadtforschung. 8(3), 157-164.

Harvey, D. (2020, March 20). Anti-Capitalist Politics in the Time of COVID-19. jacobinmag. Retrieved from https://jacobinmag.com/2020/03/david-harvey-coronavirus-political-economy-disruptions

HFB (2019, December 6). Kurzkonzept. Housing First Berlin. Retrieved from https://housingfirstberlin. de/wp-content/uploads/2019/12/HFB-Kurzkonzept.pdf

Kauppert, C. (2018). Konzeptualisierung obdachloser Menschen in Pressetexten. Technische Universität Berlin. 30 pp. (Bachelor thesis) Retrieved from https://www.linguistik.tu-berlin.de/fileadmin/fg72/ PDF/BA_Charlotte_Kauppert.pdf

Kluge, H. H. P., Jakab, Z., Bartovic, J., d'Anna, V., \& Severoni, S. (2020). Refugee and migrant health in the COVID-19 response. The Lancet, 395(10232), 1237-1239. https://doi.org/10.1016/S01406736(20)30791-1

Lewis, C., Ram, S. G., Sayed, N., \& Aditi, R. (2020, March 24). For the homeless, corona is just a cold, the worry is food. The Times of India. Retrieved from https://timesofindia.indiatimes.com/toireporter/ author-Clara-Lewis-12714.cms

Mayring, P. (2015). Qualitative Inhaltsanalyse. Grundlagen und Techniken (12th edition). Weinheim: Beltz Verlagsgruppe.

Mieder, R. (2020, March 4). Bessere Hilfe braucht valide Zahlen. Berliner Mieterverein. Retrieved from https://www.berliner-mieterverein.de/magazin/online/mm0320/obdachlosenzaehlung-valide-zahlen-sind-notwendig-um-helfen-zu-koennen-032008a.htm

Nehls, A. (2021, February 2). Kälte und Corona. Obdachlos im Pandemie-Winter. Deutschlandfunk. Retrieved from https://www.deutschlandfunk.de/kaelte-und-corona-obdachlos-im-pandemie-winter.724.de.html?dram:article_id=490563

Nunes, N. R. A., Rodriguez, A., \& Cinacchi, G. B. (2021). Health and Social Care Inequalities: The Impact of COVID-19 on People Experiencing Homelessness in Brazil. International Journal of Environmental Research and Public Health, 18(11), 5545. https://doi.org/10.3390/ijerph18115545

OECD (2021, May 27). HC3.1 Homeless Population. Affordable Housing Database. Retrieved from https:// www.oecd.org/els/family/HC3-1-Homeless-population.pdf 
Oladimeji, O., Atiba, B. P., Mbokazi, J., \& Hyera, F. L. M. (2020). The homeless, inmates and refugees in Africa in the face of Covid-19 outbreak. The Open Public Health Journal, 13(1), 306-308. https://doi. org/10.2174/1874944502013010306

Parsell, C., Clarke, A., \& Kuskoff, E. (2020). Understanding responses to homelessness during COVID-19: An examination of Australia. Housing Studies, 1-14. https://doi.org/10.1080/02673037.2020.1829564

Paula, H. C., Daher, D. V., Koopmans, F. F., Faria, M. G. A., Lemos, P. F. S., \& Moniz, M. A. (2020). No place to shelter: ethnography of the homeless population in the COVID-19 pandemic. Revista Brasileira de Enfermagem. 13(73). https://doi.org/10.1590/0034-7167-2020-0489

Pawson, H., Martin, C., Sisson, A., Thompson, S., Fitzpatrick, S., \& Marsh, A. (2021). COVID-19: Rental housing and homelessness impacts - an initial analysis. ACOSS/UNSW Poverty and Inequality Partnership Report, 7.

Perri, M., Dosani, N., \& Hwang, S. W. (2020). COVID-19 and people experiencing homelessness: Challenges and mitigation strategies. Canadian Medical Association Journal, 192(26), E716-E719. https://doi. org/10.1503/cmaj.200834

Ray, R. (2020, April 9). Why are Blacks dying at higher rates from COVID-19? Brookings. Retrieved from https://www.brookings.edu/blog/fixgov/2020/04/09/why-are-blacks-dying-at-higher-rates-fromcovid-19/

Redditt, V., Wright, V., Rashid, M., Male, R., \& Bogoch, I. (2020). Outbreak of SARS-CoV-2 infection at a large refugee shelter in Toronto, April 2020: a clinical and epidemiologic descriptive analysis. Canadian Medical Association Journal, 8(4), E819-E824. https://doi.org/10.9778/cmajo.20200165

Rollmann, N. (2020). „Corona schlug ein wie eine Bombe“ Die Situation Berliner Obdachloser während der Pandemie. Retrieved from https://74ff6daa-29f9-493b-9038-5f99677fbed3.filesusr.com/ugd/ bffcde_042ad054f8704fc1a7746747967ae7bb.pdf

Salmen, I. (2021). Bundesnotbremse beseitigt soziale Regelung für Obdachlose. Tagesspiegel. Retrieved from https://www.tagesspiegel.de/berlin/coronavirus-in-berlin-inzidenz-leicht-auf-136-5-gestiegen-793-neuinfektionen/25655678.html

SenIAS (2019, September 3). Leitlinien der Wohnungsnotfallhilfe und Wohnungslosenpolitik. Senatsverwaltung für Integration, Arbeit und Soziales. Retrieved from https://www.berlin.de/sen/soziales/ besondere-lebenssituationen/wohnungslose/

SenIAS (2020a, December 15). GEBEWO pro und Hofbräu Berlin öffnen Tagestreff für obdachlose Menschen während der Corona-Pandemie - mit gutem Essen und mehrsprachiger Sozialberatung. Senatsverwaltung für Integration, Arbeit und Soziales. Retrieved from https://www.berlin.de/sen/ias/ presse/pressemitteilungen/2020/pressemitteilung.1030788.php

SenIAS (2020b, October 1). Kältehilfe startet am 1. Oktober mit anfangs 500 Plätzen. Im Winter soll es etwa 1.000 Notübernachtungsplätze geben. Senatsverwaltung für Integration, Arbeit und Soziales. Retrieved from https://www.berlin.de/sen/ias/presse/pressemitteilungen/2020/pressemitteilung.998963.php

SenIAS (2021). Wohnungslose und von Wohnungslosigkeit bedrohte Menschen. Senatsverwaltung für Integration, Arbeit und Soziales. Retrieved from https://www.berlin.de/sen/soziales/besondere-lebenssituationen/wohnungslose/

Skzl (2020, July 21). Berlin unterstützt weiterhin den Zugang zu medizinischer Versorgung für nicht krankenversicherte Menschen - Behandlungsangebote ausgeweitet. Der Regierende Bürgermeister von Berlin - Senatskanzlei. Retrieved from https://www.berlin.de/rbmskzl/aktuelles/pressemitteilungen/2020/pressemitteilung.963652.php

Skzl (2021, April 27). Zweite SARS-CoV-2-Infektionsschutzmaßnahmenverordnung. Der Regierende Bürgermeister von Berlin - Senatskanzlei. Retrieved from https://www.berlin.de/corona/massnahmen/ verordnung/\#part1

WHO (2020). Apart Together survey: preliminary overview of refugees and migrants self-reported impact of COVID-19. Geneva: World Health Organization. 
Annex 1: Extraction and categorizing data corpus

\begin{tabular}{|c|c|c|c|}
\hline Categories & $\begin{array}{l}\text { Number of press } \\
\text { release }\end{array}$ & Date & Publishing institutions \\
\hline \multirow{2}{*}{$\begin{array}{l}\text { Emergency } \\
\text { responses } \\
\text { concerning } \\
\text { refuges }\end{array}$} & 913584 & March 30, 2020 & Senate Department for Integration, Labor and Social Affairs (SenIAS) \\
\hline & 920740 & April 16, 2021 & Senate Chancellery (Skzl) \\
\hline \multirow{5}{*}{ Nutrition } & 921677 & April 17, 2020 & District Office Pankow (BA Pankow) \\
\hline & 1024744 & December 2, 2020 & Senate Department for Integration, Labor and Social Affairs (SenIAS) \\
\hline & 1030788 & December 15, 2020 & Senate Department for Integration, Labor and Social Affairs (SenIAS) \\
\hline & 1033597 & December 21, 2020 & Senate Department for Integration, Labor and Social Affairs (SenIAS) \\
\hline & 1051043 & February 10, 2021 & Senate Department for Integration, Labor and Social Affairs (SenIAS) \\
\hline \multirow{12}{*}{$\begin{array}{l}\text { Preventive } \\
\text { care and } \\
\text { treatment }\end{array}$} & 930275 & May 11,2020 & Senate Department for Integration, Labor and Social Affairs (SenIAS) \\
\hline & 942001 & June 8,2020 & District Office Mitte (BA Mitte) \\
\hline & 1024744 & December 2, 2020 & Senate Department for Integration, Labor and Social Affairs (SenIAS) \\
\hline & 1033034 & December 18, 2020 & District Office Friedrichshain-Kreuzberg (BA Friedrichshain Kreuzberg) \\
\hline & 1064433 & March 15, 2021 & Senate Department for Integration, Labor and Social Affairs (SenIAS) \\
\hline & 1064433 & March 15, 2021 & Senate Department for Integration, Labor and Social Affairs (SenIAS) \\
\hline & 1065050 & March 16, 2021 & Senate Department for Integration, Labor and Social Affairs (SenIAS) \\
\hline & 1068518 & March 24, 2021 & Senate Department for Integration, Labor and Social Affairs (SenIAS) \\
\hline & 1070660 & March 30, 2021 & Senate Department for Integration, Labor and Social Affairs (SenIAS) \\
\hline & 1079541 & April 27, 2021 & Senate Department for Integration, Labor and Social Affairs (SenIAS) \\
\hline & 1079541 & April 27, 2021 & Senate Department for Integration, Labor and Social Affairs (SenIAS) \\
\hline & 1079819 & April 28, 2021 & Senate Department for Integration, Labor and Social Affairs (SenIAS) \\
\hline \multirow{25}{*}{$\begin{array}{l}\text { Providing and } \\
\text { expanding } \\
\text { sheltert }\end{array}$} & 911194 & March 24, 2020 & Senate Department for Integration, Labor and Social Affairs (SenIAS) \\
\hline & 925970 & April 27, 2020 & Senate Department for Integration, Labor and Social Affairs (SenIAS) \\
\hline & 927732 & April 30, 2020 & Senate Department for Integration, Labor and Social Affairs (SenIAS) \\
\hline & 930275 & May 11,2020 & Senate Department for Integration, Labor and Social Affairs (SenIAS) \\
\hline & 932293 & May 14,2020 & Senate Department for Integration, Labor and Social Affairs (SenIAS) \\
\hline & 967896 & July 31,2020 & Senate Department for Integration, Labor and Social Affairs (SenIAS) \\
\hline & 977704 & August 18,2020 & Senate Department for Integration, Labor and Social Affairs (SenIAS) \\
\hline & 998963 & October 1, 2020 & Senate Department for Integration, Labor and Social Affairs (SenIAS) \\
\hline & 1011263 & October 30, 2020 & Senate Department for Integration, Labor and Social Affairs (SenIAS) \\
\hline & 1024744 & December 2, 2020 & Senate Department for Integration, Labor and Social Affairs (SenIAS) \\
\hline & 1030788 & December 15, 2020 & Senate Department for Integration, Labor and Social Affairs (SenIAS) \\
\hline & 1036775 & January 6, 2021 & Senate Department for Integration, Labor and Social Affairs (SenIAS) \\
\hline & 1039361 & January 13, 2021 & Senate Department for Integration, Labor and Social Affairs (SenIAS) \\
\hline & 1042431 & January 20, 2021 & Senate Department for Integration, Labor and Social Affairs (SenIAS) \\
\hline & 1045120 & January 27, 2021 & Senate Department for Integration, Labor and Social Affairs (SenIAS) \\
\hline & 1048199 & February 3, 2021 & Senate Department for Integration, Labor and Social Affairs (SenIAS) \\
\hline & 1049734 & February 2, 2021 & Senate Department for Integration, Labor and Social Affairs (SenIAS) \\
\hline & 1051043 & February 10, 2021 & Senate Department for Integration, Labor and Social Affairs (SenIAS) \\
\hline & 1051151 & February 10, 2021 & District Office Steglitz-Zehlendorf (BA Steglitz-Zehlendorf) \\
\hline & 1053923 & February 17, 2021 & Senate Department for Integration, Labor and Social Affairs (SenIAS) \\
\hline & 1056646 & February 24, 2021 & Senate Department for Integration, Labor and Social Affairs (SenIAS) \\
\hline & 1070974 & March 31, 2021 & Senate Department for Integration, Labor and Social Affairs (SenIAS) \\
\hline & 1072537 & April 7, 2021 & Senate Department for Integration, Labor and Social Affairs (SenIAS) \\
\hline & 1074848 & April 14, 2021 & Senate Department for Integration, Labor and Social Affairs (SenIAS) \\
\hline & 1077205 & April 21, 2021 & Senate Department for Integration, Labor and Social Affairs (SenIAS) \\
\hline
\end{tabular}




\begin{tabular}{|l|c|l|l|}
\hline \multicolumn{1}{|c|}{ Categories } & $\begin{array}{c}\text { Number of press } \\
\text { release }\end{array}$ & \multicolumn{1}{|c|}{ Date } & \multicolumn{1}{c|}{ Publishing institutions } \\
\hline $\begin{array}{l}\text { Repression } \\
\text { on people } \\
\text { experiencing } \\
\text { homelessness }\end{array}$ & 1049876 & February 5, 2021 & District Office Lichtenberg (BA Lichtenberg) \\
\hline \multirow{4}{*}{$\begin{array}{l}\text { Tenant } \\
\text { protection }\end{array}$} & 6873 & April 9, 2020 & Senate Department for Urban Development and Housing (SenSW) \\
\cline { 2 - 5 } & 6967 & September 29, 2020 & Senate Department for Urban Development and Housing (SenSW) \\
\cline { 2 - 4 } & 997842 & September 29, 2020 & Senate Department for Urban Development and Housing (SenSW) \\
\cline { 2 - 4 } & 1033923 & December 22, 2020 & Senate Chancellery (Skzl) \\
\hline
\end{tabular}

